\title{
Simultaneous Synthesis of Heat Exchanger Networks Considering Steam Supply and Various Steam Heater Locations
}

\author{
Yao Sheng ${ }^{1}$, Linlin Liu ${ }^{1}{ }^{*}$, Yu Zhuang ${ }^{2}$, Lei Zhang ${ }^{1}\left(\mathbb{D}\right.$ and Jian Du ${ }^{1}$ \\ 1 School of Chemical Engineering, Institute of Chemical Process Systems Engineering, Dalian University of \\ Technology, Liaoning, Dalian 116024, China; shengyao@mail.dlut.edu.cn (Y.S.); keleiz@dlut.edu.cn (L.Z.); \\ dujian@dlut.edu.cn (J.D.) \\ 2 Key Laboratory of Liaoning Province for Desalination, School of Energy and Power Engineering, \\ Dalian University of Technology, Liaoning, Dalian 116024, China; zhuangyu@mail.dlut.edu.cn \\ * Correspondence: liulinlin@dlut.edu.cn
}

Received: 10 February 2020; Accepted: 17 March 2020; Published: 20 March 2020

check for updates

\begin{abstract}
In process industries, the heating gap in heat exchanger networks (HENs) is normally compensated by the steam generated from a utility system, thus these two mutually influencing systems should be designed as a whole through establishing structural interrelationships. In this work, an improved stage-wise superstructure of HENs is proposed to integrate with a Rankine cycle-based utility system. Inner- and inter-stage heaters are considered in the new structure. Furthermore, the selection of steam in different levels is also investigated, extending the possibilities of steam utilization in HENs and generation in utility systems. The presented methodology is able to realize the optimal design of HENs by considering the supply and utilization of steam. Heaters' allocations, matches of streams, steam distribution and utilization are optimized accompanying with the trade-off amongst equipment investment, fuel consumption and power generation in objective, which is highly related to the final structure of the system. The optimization problem is formulated into a mixed-integer non-linear programming (MINLP) model and solved towards the lowest total annual cost (TAC) of the entire system. Finally, a case study with two scenarios is studied. The detailed results are given and analyzed to demonstrate the benefit from structural improvement.
\end{abstract}

Keywords: improved superstructure; HENs; utility system; steam heater; MINLP

\section{Introduction}

With the continuous increase of energy consumption in industrial processes, the energy crisis has further intensified on account of the limited fossil energy reserves. Energy prices are also on the rise at the same time, which drives the pursuit of energy-saving technologies and methods. Heat exchanger networks (HENs) are an inevitable part in processing enterprises for heat recovery. Hot process streams that need to be cooled down and cold process streams that need to be heated up widely exist in process enterprises. Synthesis of HENs is able to obtain HEN structures with reasonable matches between these hot and cold process streams and recover waste heat to the greatest extent. Thus the additional utility consumption will be greatly reduced. On the other hand, utility systems based on steam power cycles are one of the major sources which can export multi-level steam and power to industrial enterprises from a single primary energy source. Energy consumption in utility systems accounts for a large proportion of total industrial energy consumption, which makes it meaningful to improve energy efficiency of utility system. These two parts, the HEN and the utility system, are involved the whole process of energy supply, energy consumption and energy saving. While in implementation, the utility 
system is usually designed independently with its connections with the processes ignored, so the simultaneous synthesis and optimization of HENs and utility systems should be improved.

Determining the use of utilities is always one important content in HEN synthesis, either within a sequential synthesis method or a simultaneous synthesis method. In pinch technology [1] and the trans-shipment model-based method [2], the consumption of cold and hot utilities is targeted by monitoring of pinch point locations, before designing the network structure in terms of paring hot and cold streams; in the superstructure-based simultaneous method [3], utility consumption is optimized by the trade-off with the capital costs of heat exchangers. Although the study of HEN synthesis has been developed for decades, there are still deficiencies. For example, most previous works on HEN synthesis only used one type of utility at the stream end and assumed that the temperatures of these utilities are able to satisfy all the hot and cold demands, while the fact is that the utility can be in many forms, such as flue gas, steam with different temperatures and hot water. Thus, studies have been launched to investigate the reasonable use of these utilities in HEN synthesis. Costa and Queiroz [4] introduced an extension of the problem table algorithm to optimize and analyze multiple utilities selection and utilization instead of using a grand composite curve. Although the advantages of multi-level utility selection are not analyzed, it is an effective way to optimize multi-level utility utilization with a table algorithm. Salama [5] developed a simple and direct numerical geometry-based technique to target optimal assignment of multiple utilities, but only the heat load was optimized without considering the equipment investment. Shenoy et al. [6] presented a cost-optimal targeting methodology considering the trade-off between energy consumption and equipment investment simultaneously. Optimal selections and loads for multiple utilities were determined based on pinch analysis and the cheapest utility principle. In essence it was still a sequential method, which makes it impossible to achieve a real trade-off between energy and equipment costs. Isafiade and Fraser [7] studied an interval-based MINLP superstructure where the intervals were defined according to the supply and target temperatures of hot or cold process streams. The superstructure model was then applied to HEN synthesis with multi-level available utilities, trading off operating and capital costs for each type of utility. Many nonlinear terms were ignored by mixing split streams at equal temperature, which made the obtained results improvable. Ponce-Ortega et al. [8] developed a stage-wise superstructure that allowed existence of intermediate placement of multiple utilities within each stage. Load and placement of multiple utilities were treated as optimization variables by employing disjunctive programming formulation, rather than regarding utilities as process streams and setting their capacity flowrates as optimization variables. Na et al. [9] proposed a modified superstructure that contained utility sub-stages between adjacent stages. Series utility locations were fixed to facilitate convergence. These studies greatly expanded the design space of the HEN structure and utilization of multiple utilities, but the selection of multiple utilities was mainly based on their price, and the interactions with other systems was not investigated in depth. Zhang et al. [10] explored a new HEN superstructure presentation named the stage-wise chessboard model for management of feasible research regions. A random walk algorithm was employed to lower the calculation load. The problem can be solved faster, but many possible matches are not included in the proposed superstructure because it was equivalent to a stage-wise superstructure with only one stage. Pavão et al. [11] considered the solving difficulty of complex mathematical models resulting from an enhanced stage-wise superstructure which includes the use of multiple utilities at single stream branches. An enhanced meta-heuristic solution method was presented to handle the complex mathematical model, and the superstructure had no difference from the superstructure in Ponce et al. [8] mentioned above. Ma et al. [12] launched multi-objective optimization of interplant HENs operated for multi-periods, which used steam as the heat transfer medium. This research analyzed the conflict between environmental impacts and exchanger investment according to the trade-off between utility consumption and exchanger areas in a case study, but the influence of multi-level steam distribution on the environmental and economic objectives was ignored. Besides, power generation in the utility system was not included in the objective function either, thus the HEN and utility system were not globally integrated. 
HENs have been further integrated with utility systems based on their close interactions. Klemeš et al. [13] studied the simultaneous synthesis of a production process and a utility system based on pinch analysis methodology in a total site integration, but the optimization was carried out after integration within a single plant was completed in advance. Thus the heat recovery and utility system were not optimized simultaneously. Liew et al. [14] optimized the design and operation of a centralized utility system to adapt to shutdowns or process upsets, making a trade-off between operational adaptability and operating costs. Detailed synthesis of the HEN was not included either. Chen and Lin [15] proposed a MINLP model to design a steam network and heat recovery network simultaneously. Hot and cold utilities were only placed at the stream ends, while steam can be generated within an inner-stage to promote energy synergy among plants. Different from previous total site integrations, the heat demand of the HEN is unknown before the design stage, but this research did not consider the utilization of multiple types of utilities within the inner-stage. Hipólito-Valencia et al. [16] combined an organic Rankine cycle with HEN and converted waste heat into mechanical energy, which provided more inspiration for the combination of HEN and other processes. Goh et al. [17] synthesized a HEN and utility system simultaneously, but the minimum operating cost, hot and cold utility demands were determined in advance through multiple cascade automated targeting, without realizing the overall optimization. Luo et al. [18] integrated a HEN with a utility system, using the sensible heat of steam condensate to heat cold process streams. Besides, waste heat of the hot process streams was recovered to preheat boiler feedwater, but the combination was allocated at stream ends, which limited the optimization space compared with the superstructure considering inner-stage utility utilization. Martelli et al. [19] developed a two-stage sequential synthesis algorithm to solve the nonconvex MINLP problem derived from the simultaneous synthesis of HEN and utility systems. An isothermal mixing assumption was made and the utility systems were set as process streams, which will increase the problem-solving complexity. Elsido et al. [20] have worked on the simultaneous synthesis of utility systems, Rankine cycles and heat exchanger networks. However, their mathematical model was established based on a $p$ - $h$ superstructure but not a stage-wise superstructure. The main purpose was proposing an ad hoc bilevel decomposition method to improve solution efficiency but not optimizing the utility utilization through improving the superstructure. The simultaneous optimization of multi-plant heat integration using steam as intermediate fluid described in Chang et al. [21] reflected the utilization of energy within the inner-stage, but the steam used within the inner-stage was generated from process streams, and the utility system was not considered completely here. Huang et al. [22] extended their research to the simultaneous optimization of a heat exchanger network, steam Rankine cycle and organic Rankine cycle, but the steam utilization and ORC evaporator were placed at stream ends, and inner- and inter-stage improvements were not considered in the superstructure.

Research about HEN synthesis and utility system is summarized here. On one hand, improvements have been made to provide more matching possibilities in HENs and obtain HEN configurations closer to an optimal solution. On the other hand, utility systems and HENs were considered simultaneously to strengthen the heat integration. In total site heat integration using the sequential method, the utility system was usually designed after the determination of heating demand, making it unable to obtain the optimal trade-off between equipment investment and operating cost. As for the mathematical programming method which can perform the design of HENs while optimizing the operation of the utility system, either the heaters were placed at stream ends, or the operating parameters and power generation of utility system were not included, even though the utilization of utilities was considered within the inner-stage. Thus, in order to achieve a better network management, an improved superstructure considering multiple utilities utilization within the inner- and inter-stage is presented and integrated with the utility system based on a Rankine cycle. Multiple utilities (steam in different pressure levels) are produced in cascade in the utility system with concurrently power generation. The structure of the HEN and the operation of the utility system are simultaneously influenced by the placement and distribution of multiple utilities, leading to a trade-off among capital costs, fuel costs and power generation profits. It should be noted that steam is not regarded as process stream but rather 
as an additional heating source in this study, so the established mathematical model corresponding to the special HEN superstructure including inner- and inter-stage heaters is different from previous formulations, by which the steam in any alternative level can be selected as long as the temperature difference demand is met. Finally, cases are illustrated to show the goals of this paper, demonstrating that multi-level steam selection and utilization within the inner- and inter-stage will provide a larger optimization space for steam distribution, power generation and fuel consumption of the utility system, achieving better economic performance of the whole system.

\section{Problem Statement}

A synthesis of HEN involving the optimization of steam supply and utilization is desired in this study, and the entire problem can be described as follows: a set of hot and cold process streams which must be cooled and heated are given with their heat capacity flowrates, supply temperatures, target temperatures and heat transfer coefficients. To compensate the heating gap, a utility system is optimized to produce appropriate steam, in terms of multiple paralleled mains/levels with different pressures and as well temperatures. These steam branches are usually classified as high pressure steam, medium pressure steam, and low pressure steam (HPS, MPS, LPS), etc. In this study, a set of steam alternatives with certain pressures and temperatures are given for selection. The utility system follows the basic process of a Rankine cycle, but the properties and quantity of generated steam must be optimized towards the best benefit of the whole system. Additionally, all the cost-related parameters are also given in order to assess cold utility cost, fuel cost, equipment investment (for heat exchangers, boilers and turbines) and the profit from selling power. The integration problem aims at achieving the most cost-efficient configuration of steam supply HEN, by making trade-offs amongst the contribution of the mentioned economic sectors in the total annualized cost. For this purpose, the interaction between the two sub-systems must be comprehensively explored and the network details, such as fuel consumption, steam generation and allocation, generated power, stream matches, heat loads, operating temperatures, and area of heat exchangers must be optimized. In order to alleviate the solving difficulties caused by a complicated mathematical presentation, it is assumed that: (1) the heat capacity and heat transfer coefficient are constant throughout the whole process; (2) the heat exchange task is completed in a countercurrent heat exchanger; (3) all operations are adiabatic, ignoring the heat loss and mass loss; (4) transportation problems are not taken into account; (5) only the primary units in the utility system are considered, ignoring the auxiliary devices.

\section{Method Overview}

To solve the mentioned synthesis problem, an optimization-based method is developed and presented in this study. Since a synthesis solution is characterized by two aspects: the network structure (referring mainly to where to exchange heat and whether generate the steam) and the network parameters (which should be quantified, such as flowrate, temperature, heat exchange areas), a superstructure embedding all potential network configurations is introduced as the first step of the method, to offer decision options for the network structure, then a mathematical model is formulated to perform the optimization, making an automatic determination for both network structure and network parameters. Although this method is developed from the general concepts of HEN and utility systems, the major contribution of this work is still worth mentioning, that is, the utilization of steam in the HEN is extended by considering various locations along streams, being in series or/and parallel with stream-stream heat exchange, and meanwhile not only with the given utility steam but having the generation and allocation of steam integrated, such that the interaction between HEN and utility system can be explored with more space. It is believed that better design solutions will be obtained by using this method. For clarity, the superstructure is described in Section 4, followed by the mathematical model presentation in Section 5. 


\section{Superstructure}

Figure 1 presents the superstructure of the proposed integration problem. All potential configuration alternatives of the HEN are displayed by considering the utilization of steam. For the HEN side, two hot process streams and two cold streams are used to exhibit the features of the stage-wise superstructure. Since the heaters involving steam could be before, after and in parallel with stream-stream heat exchangers, new stages are introduced in the superstructure to fully explore the utilization of steam. It should be noticed that the stages are divided into two types-the inner-stage and the inter-stage - which are alternately arranged. Within each inner-stage, a cold process stream can be split into multiple branches to perform the heat exchange with hot process streams and steam simultaneously. After that, the branches are mixed non-isothermally into a main stream and go into the inter-stage, where only steam is allowed to heat the cold streams. Inter-stage heaters are allowed at both the start and end of cold streams, so the inter-stage number is one more than that of inner-stages. This arrangement could provide much more matching options between cold process streams and steam with limited stages, enriching the configurations of the superstructure. Hot streams are operated in the traditional manner, cooled down by cold process streams within inner-stages and cooling water at stream ends.

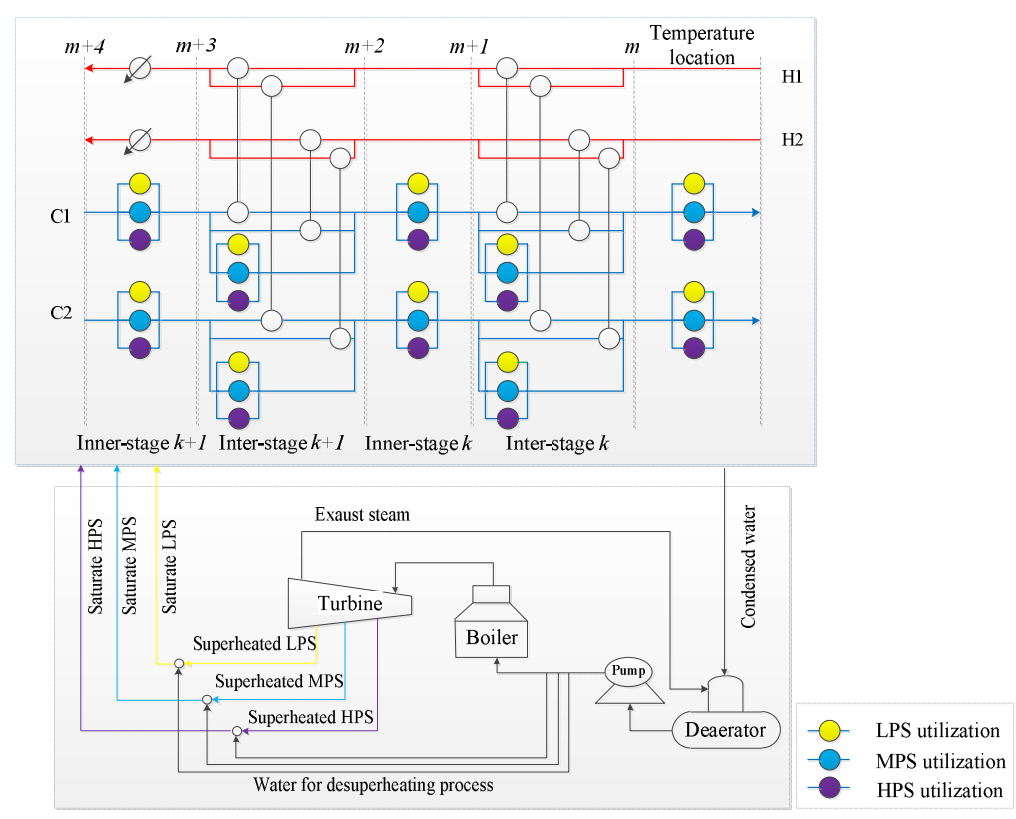

Figure 1. Superstructure for combined HEN and utility system.

The operation of utility system is in typical Rankine cycle: the highest pressure superheated steam is generated in a boiler through combusting fuel, and then sent into a turbine to generate multi-level superheated steam with turbine condensed steam extracted and condensed at the end, producing power at the same time. The superheated steam needs to be desuperheated by mixing with water from the deaerator before being sent to the HEN as saturated steam. After heating the process streams, the condensed water returns to the deaerator, and splits into two parts after the operation, part is sent to the boiler and evaporated into superheated steam, and the residue is mixed with multi-level superheated steam to obtain saturated steam, finishing a cycle. Although the flowsheet of the utility system is quite certain, the possibilities of steam generation and utilization in the HEN need to be determined within the design.

Based on the presented superstructure, a mathematical model can be formulated to determine the optimal network structures and network parameters. In this work, considering the deaerator is an energy-consuming unit, another system without deaerator is also investigated, e.g., using a chemical 
deaeration technique. The resultant variation in structure is that part of the condensed water is mixed with the corresponding superheated steam, while the rest flows back to the boiler directly.

\section{Mathematical Formulation}

The synthesis of the overall network is performed with a mathematical model in MINLP. The mass balances, heat balances, feasibility constraints, and formulas for device related and cost related calculations are all given to describe the characteristics contained in the superstructure. The model is decomposed into three parts for understanding: model for HEN synthesis, constraints for the utility system, and the objective function. Implementation of the model is also introduced.

As mentioned in problem statement, the given parameters in the model contain:

(1) Stream parameters: supply and target temperatures, flowrates, heat transfer coefficients;

(2) Cost-related parameters: unit price of cold utility, fuel and power; cost parameters for heat exchanger, boiler and turbine;

(3) Parameters of the steam options: enthalpy of saturate steam, superheated steam, condensate, and water from deaerator.

The notation for these parameters is listed in the Nomenclature section. The rest of the notations in the model indicate the variables that should be determined within model implementation. The binary variables $\left(z_{i, j, k}, z c u_{i}, z h u_{j, k, n}, z h u s_{j, k, n}\right)$ indicate the existences of heat exchangers, determining the structure of the network, and the continuous variables (including inlet and outlet temperatures, stream flowrate, heat load, heat exchange area of each exchanger, quantity of generated steam and power, and cost results) refer to the operation and assessment aspects of the obtained network.

\subsection{Model for HEN Synthesis}

The model of the HEN is formulated to determine the existences of heat exchangers, operating parameters of heat exchangers, required heat transfer area, capital cost and utility cost. The model formulation presented below consists mainly of mass and energy balance equations. Temperature feasibility constraints are also included. Several sets are defined to assist the expression of involved parameters and variables: $i \in I, j \in J$ denote hot and cold process streams, $k \in K$ denotes temperature interval of inner- and inter-stage, $m \in M$ is the order of temperature location which is corresponding to stage $k, n \in N$ denotes the steam levels in different pressures.

Heat balances of hot and cold process streams are defined by Equations (1) and (2), wherein $F H_{i}$ and $F C_{j}$ denote the total heat capacity flowrates of a hot process stream $i$ and a cold process stream $j$; thin ${ }_{i}$, thout ${ }_{i}$, tcin $_{j}$, tcout $t_{j}$ denote supply and target temperatures of streams; $q_{i j, k, k}$, represents the heat load of a heat exchanger between hot and cold streams; $q h u_{j, k, n}$ and $q h u s_{j, k, n}$ are the heat satisfied by steam $n$ within inter-stage and inter-stage, respectively. $q h u_{j, 0, n}$ is the heat satisfied by steam $n$ at the end of cold stream $j$. Equation (1) is used to ensure each hot stream is cooled from its supply temperature to target by performing adequate heat exchanges with cold streams and cold utility. Analogously, Equation (2) is involved to guarantee that the required heat of each cold stream is satisfied by inner-stage stream-stream exchange, inter-stage stream-steam exchange (including the matching at stream end) and inner-stage stream-steam exchange:

$$
\begin{gathered}
\sum_{j} \sum_{k} q_{i, j, k}+q c_{i}=F H_{i}\left(\text { thin }_{i}-\text { thout }_{i}\right) \\
\sum_{i} \sum_{k} q_{i, j, k}+\sum_{k} \sum_{n} q h u_{j, k, n}+\sum_{k} \sum_{n} q h u s_{j, k, n}+\sum_{n} q h u_{j, 0, n}=F C_{j}\left(\text { tcout }_{j}-\text { tcin }_{j}\right)
\end{gathered}
$$

Equations (3)-(6) present the energy balances of hot and cold process streams within innerand inter-stage. $t i_{i, m}$ and $t j_{j, m}$ are temperature locations of process streams corresponding to stage $k$. Equation (3) shows that, within inner-stage, hot streams only exchange heat with cold streams. 
Equation (4) defines that cold process streams can be heated up by hot process stream and steam $n$ in parallel form within inner-stage $k$, and more than this, the inter-stage heating from steam is also available, as indicated in Equation (5). The relationship of temperature location $m$ and stage $k$ is worth mentioning here. In view of the existence of inner- and inter-stage, the presentation of temperature location becomes complicated. In order to enhance the universality of the model, constraints are employed to determine the relationship of $m$ and $k$. For inner-stage $k$, the left temperature location $m$ of process stream corresponds to $2 k-1$, right temperature location $m$ of process stream corresponds to $2 k$. While for inter-stage $k$, its left temperature location is the same as right temperature of inner-stage $k$, so its left temperature location is $2 k$, and the right temperature location corresponds to $2 k+1$ :

$$
\begin{gathered}
F H_{i}\left(t i_{i, m-1}-t i_{i, m}\right)=\sum_{j} q_{i, j, k} \quad m=2 k \\
F C_{j}\left(t j_{j, m-1}-t j_{j, m}\right)=\sum_{i} q_{i, j, k}+\sum_{n} q h u s_{j, k, n} \quad m=2 k \\
F C_{j}\left(t j_{j, m}-t j_{j, m+1}\right)=\sum_{n} q h u_{j, k, n} \quad m=2 k \\
F C_{j}\left(t \text { cout }_{j}-t j_{j, m}\right)=\sum_{n} q h u_{j, 0, n} \quad m=1
\end{gathered}
$$

Equations (7)-(9) express the mass balances of hot and cold process streams within the innerand inter-stages. A hot stream must be split into branches to perform the potential heat exchanges with cold streams within each inner-stage (Equation (7)), but for a cold stream, there are two kinds of matches within inner-stage $k$, with hot process streams and with steam (Equation (8)). For inter-stages, split branches can only match with steam (Equation (9)):

$$
\begin{gathered}
F H_{i}=\sum_{j} f h s_{i, j, k} \\
F C_{j}=\sum_{i} f c s_{i, j, k}+\sum_{n} f c s p_{j, k, n} \\
F C_{j}=\sum_{n} f c s k_{j, k, n}
\end{gathered}
$$

The characteristics of an exchanger include its location, inlet and outlet temperatures, hot and cold stream (branch) flowrates, heat load and heat transfer area. Due to the variety of the exchangers in the presented superstructure, the models for exchangers are presented in five sets: inner-stage stream-stream exchangers, inter-stage stream-steam exchangers, inner-stage stream-steam exchangers, heaters at end of cold process streams, and coolers at the end of hot streams. All these exchangers are expressed with similar heat balances and area equations in the modeling.

Equations (10)-(16) are used to calculate the heat load $q_{i, j, k}$ and heat transfer area $A_{i, j, k}$ of heat exchangers between hot and cold streams within inner-stage $k$. Heat balance Equations (10) and (11) are used to constraint the inlet and outlet temperatures of the unit that, the released heat from hot stream $i$ equals to that obtained by the pairing cold stream $j . d t i j 1_{i, j, k}$ and $d t i j 2_{i, j, k}$ in Equations (12) and (13) denote the temperature difference at the two sides of the heat exchanger. In order to circumvent the presence of logarithm and the resultant difficulty in model solving, the logarithmic mean temperature difference used for transfer area calculation (Equation (15)) is approximated by Equation (14) [23]. In the model, binary variable $z_{i, j, k}$ is employed to indicate the existence of heat exchangers, that is, $z_{i, j, k}$ $=1$ means the heat exchanger exists, otherwise the exchanger is not involved. Heat loads are highly 
related to the locations of exchangers, so Equation (16) is used by defining sufficiently large constant $Q_{\max }$ to assist with the constraint:

$$
\begin{gathered}
q_{i, j, k}=f h s_{i, j, k}\left(t i_{i, m-1}-t h_{i, j, k}\right) \quad m=2 k \\
q_{i, j, k}=f c s_{i, j, k}\left(t c_{i, j, k}-t j_{j, m}\right) \quad m=2 k \\
d t i j 1_{i, j, k} \leq t i_{i, m-1}-t c_{i, j, k}+T_{\max }\left(1-z_{i, j, k}\right) \quad m=2 k \\
d t i j 2_{i, j, k} \leq t h_{i, j, k}-t j_{j, m}+T_{\max }\left(1-z_{i, j, k}\right) \quad m=2 k \\
\Delta T i j_{i, j, k}=\left(d t i j 1_{i, j, k} \times d t i j 2_{i, j, k} \times\left(d t i j 1_{i, j, k}+d t i j 2_{i, j, k}\right) \times 0.5\right)^{1 / 3} \\
A_{i, j, k}=q_{i, j, k} /\left(h \times \Delta T i j_{i, j, k}\right) \\
q_{i, j, k} \leq z_{i, j, k} \times Q_{\max }
\end{gathered}
$$

In similar way, Equations (17)-(23) are included to describe the steam heaters within each inner-stage. It is stipulated that steam, at most one type, is allowed for each possible stream-steam match, so Equation (22) is introduced into the model, by using $z h u s_{j, k, n}$ to denote the existences of the heaters:

$$
\begin{gathered}
\text { qhus } s_{j, k, n}=f \operatorname{csp}_{j, k, n}\left(t \operatorname{csp} p_{j, k, n}-t j_{j, m}\right) \quad m=2 k \\
d t h s 1_{j, k, n} \leq t h u s_{j, k, n}-t c s p_{j, k, n}+T_{\max }\left(1-z h u s_{j, k, n}\right) \quad m=2 k \\
d t h s 2_{j, k, n} \leq t h u s_{j, k, n}-t j_{j, m}+T_{\max }\left(1-z h u s_{j, k, n}\right) \quad m=2 k \\
\Delta \operatorname{Thus}_{j, k, n}=\left(d t h s 1_{j, k, n} \times d t h s 2_{j, k, n} \times\left(d t h s 1_{j, k, n}+d t h s 2_{j, k, n}\right) \times 0.5\right)^{1 / 3} \\
\text { Ahus }_{j, k, n}=q h u s_{j, k, n} /\left(h 1 \times \Delta \text { Thus }_{j, k, n}\right) \\
\sum_{n} z h u s_{j, k, n} \leq 1 \\
\text { qhus }_{j, k, n} \leq z h u s_{j, k, n} \times Q_{\max }
\end{gathered}
$$

Equations (24)-(30) are formulated to determine the steam heater within each inter-stage. $z h u_{j, k, n}$ denotes the existence of the heater having steam $n$ involved. Equation (29) is employed to ensure that a cold process stream can only be heated up by one steam at most within each inter-stage:

$$
\begin{gathered}
f c s k_{j, k, n}\left(t j_{j, m}-t j_{j, m+1}\right)=q h u_{j, k, n} \quad m=2 k \\
d t h 1_{j, k, n} \leq t h u_{j, k, n}-t j_{j, m}+T_{\max }\left(1-z h u_{j, k, n}\right) \quad m=2 k \\
d t h 2_{j, k, n} \leq t h u_{j, k, n}-t j_{j, m+1}+T_{\max }\left(1-z h u_{j, k, n}\right) \quad m=2 k \\
\Delta T h u_{j, k, n}=\left(d t h 1_{j, k, n} \times d t h 2_{j, k, n} \times\left(d t h 1_{j, k, n}+d t h 2_{j, k, n}\right) \times 0.5\right)^{1 / 3} \\
A h u_{j, k, n}=q h u_{j, k, n} /\left(h 1 \times \Delta T h u_{j, k, n}\right) \\
\sum_{n} z h u_{j, k, n} \leq 1 \\
q h u_{j, k, n} \leq z h u_{j, k, n} \times Q_{\max }
\end{gathered}
$$

Equations (31)-(37) are employed to determine the size of the heaters at the end of cold process streams. As mentioned in the superstructure section, the number of inter stages is one more than that of inner stages, so the exchange for this stage is expressed with the subscript ' 0 ':

$$
f \operatorname{csk}_{j, 0, n}\left(\text { tcout }_{j}-t j_{j, m}\right)=q h u_{j, 0, n} \quad m=1
$$




$$
\begin{gathered}
d t h 1_{j, 0, n} \leq t h u_{j, 0, n}-t \text { cout } \\
j \\
d t h 2_{j, 0, n} \leq t h u_{j, 0, n}-t j_{j, m}+T_{\max }\left(1-z h u_{j, 0, n}\right) \\
\Delta T h u_{j, 0, n}=\left(d t h 1_{j, 0, n} \times d t h{\left.u_{j, 0, n}\right)}_{j, n} \times\left(d t h 1_{j, 0, n}+d t h 2_{j, 0, n}\right) \times 0.5\right)^{1 / 3} \\
A h u_{j, 0, n}=q h u_{j, 0, n} /\left(h 1 \times \Delta T h u_{j, 0, n}\right) \\
\sum_{n} z h u_{j, 0, n} \leq 1 \\
q h u_{j, 0, n} \leq z h u_{j, 0, n} \times Q_{\max }
\end{gathered}
$$

Equations (38)-(44) present the calculation of heat load $q c_{i}$ and heat transfer area $A c u_{i}$ of the cooler at $i$ th stream end. $t c u_{\text {in }}$ and $t c u_{o u t}$ are the specified inlet and outlet temperatures of cold utility. $z c u_{i}$ denotes the existence of a cooler:

$$
\begin{gathered}
F H_{i}\left(t i_{i, m}-\text { thout }_{i}\right)=q c_{i} \quad m=M \\
A c u_{i}=q c_{i} /\left(h \times \Delta T c u_{i}\right) \\
d t c u 1_{i} \leq t i_{i, m}-t c u o u t+T_{\max }\left(1-z c u_{i}\right) \quad m=M \\
d t c u 2_{i} \leq \text { thout }_{i}-t c u i n+T_{\max }\left(1-z c u_{i}\right) \\
\Delta T c u_{i}=\left(d t c u 1_{i} \times d t c u 2_{i} \times\left(d t c u 1_{i}+d t c u 2_{i}\right) \times 0.5\right)^{1 / 3} \\
q c_{i} \leq z c u_{i} \times Q_{\max }
\end{gathered}
$$

\subsection{Constraints for the Utility System}

The utility system consists of a boiler, turbine and deaerator. Steam at different pressure levels is extracted from the turbine as a utility. Equation (44) presents the required heat load of steam $n$, qsteam $_{n}$, equaling to that consumed in inter-stage steam-steam exchanges and inner-stage steam-steam exchanges. The mass flow is deduced from Equation (45), wherein $l$ heat ${ }_{n}$ is the latent heat of saturated steam $n$ :

$$
\begin{gathered}
\text { qsteam }_{n}=\sum_{j} q h u_{j, 0, n}+\sum_{j} \sum_{k} q h u_{j, k, n}+\sum_{j} \sum_{k} q h u s_{j, k, n} \\
\text { msteam }_{n}=\text { qsteam }_{n} \times \text { ahour } \times 3600 / \text { lheat }_{n}
\end{gathered}
$$

Superheated steam extracted from the turbine is desuperheated by boiler feedwater from the deaerator. Equations (46)-(48) give the mass and heat balances for this process, according to the model of Luo et al. [18]. Saturated steam is obtained after mixing superheated steam and the boiler feed water which comes from the deaerator. Equations (46) and (47) describe the mass and heat balances of this desuperheating process, wherein enth denotes the enthalpy of each involved stream/steam. As all condensate water of saturated steam is mixed with exhaust steam in the deaerator at the specified operating temperature of the device, the flow rate of the exhaust steam must be constrained by the balance of the deaerator as indicated in Equation (48), wherein $m_{\text {ext }}$ denotes the mass flow of exhaust steam from turbine.

$$
\begin{gathered}
\text { msteam }_{n}=\text { msteam }_{\text {superheated }, n}+m w_{\text {deaerator }, n} \\
\text { msteam }_{n} \times \text { enth }_{n}=m w_{\text {deaerator }, n} \times \text { enth }_{\text {deaerator }, n}+\text { ssteam }_{\text {superheated }, n} \times \text { enth }_{\text {superheated }, n} \\
\sum_{n} \text { msteam }_{n} \times \text { enth }_{\text {condensate }, n}+m_{\text {ext }} \times \text { enth }_{\text {ext }}=\left(\sum_{n} \text { msteam }_{n}+m_{\text {ext }}\right) \times \text { enth }_{\text {deaerator }}
\end{gathered}
$$

Equations (49)-(52) are used to calculate economy-related factors. Equation (49) gives the power generation model of the steam turbine, wherein msteam $_{z}$ is the total mass flow through subsection $z$ of the turbine, equaling the sum of the steam at lower pressure level. As shown, the quantity of generated 
power is determined by the enthalpy difference of the inlet and outlet superheated steam as well as the steam flow rate through each section. The costs of fuel, turbine and boiler, which are highly-related to steam distribution and power generation, are obtained through Equations (50)-(52) [15], respectively. Fuel cost is calculated in Equation (50), wherein the required heat load for generating steam from condensate to superheated state is determined by steam flow rate, $\sum_{n} m$ steam $_{\text {superheated }, n}$, and unit enthalpy difference of the material in and out the boiler, $\left(e n t h_{\text {boil,out }}-e n t h_{\text {boil,in }}\right)$. Accordingly, the consumption of fuel can be calculated based on the heat content of fuel, heatcap, and boiler efficiency, effboil. As shown in Equations (51)-(52), the capital cost of the turbine is determined by the quantity of generated power and the capital cost of the boiler depends on the amount of steam generated:

$$
\begin{gathered}
w^{\text {total }}=\sum_{z} \text { msteam }_{z} \times\left(\text { enth }_{\text {superheated }, z}^{\text {in }}-\text { enth }_{\text {superheated }, z}^{\text {out }}\right) \times e f f t u r b / 3600 \\
C_{\text {fuel }}=\left(\left(\text { enth }_{\text {boil,out }}-e_{\text {enth }} \text { boil,in }\right) \times \sum_{n} \text { msteam }_{\text {superheated }, n}\right) \times c f u e l /(\text { effboil } \times \text { heatcap }) \\
C_{\text {tur }}=a_{\text {tur }}+b_{\text {tur }} \times \text { wt }^{\text {total }} / \text { ahour } \\
C_{\text {boil }}=a_{\text {boil }}+\left(b_{\text {boil }} \times\left(\sum_{n} \text { msteam }_{\text {superheated }, n}+m_{\text {ext }}\right)\right) / \text { ahour }
\end{gathered}
$$

\subsection{Objective Function}

The aim the study is to obtain an integrated system with the minimum total annual cost (TAC). As presented in the objective function of Equation (53), the TAC equals the total economic cost minus the profit from selling power. Economic cost is composed by the capital cost for exchangers, turbine, boiler, and the operating cost for fuel and cold utility consumption. The exchangers are assessed in general form $C F+C E \times A^{\beta}$, in which $C F, C E$ and $\beta$ denote the fixed charge of heat exchanger,

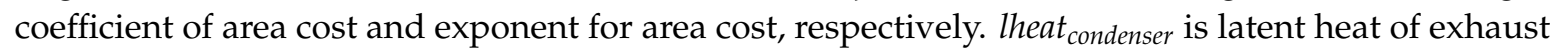
steam from turbine end. The costs of turbine, boiler and fuel are obtained according to Equations (50)-(52). The quantities of consumed cold utility and generated power are determined by Equations (38) and (49), then the corresponding cost and profit are calculated by multiplying the unit prices $C_{c u}$ and $C_{\text {pow }}$ :

$$
\begin{aligned}
\operatorname{minTAC} & =\sum_{i}\left(C F_{c u, i} \times z c u_{i}\right)+\sum_{i} \sum_{j} \sum_{k}\left(C F_{i, j, k} \times z_{i, j, k}\right)+\sum_{j} \sum_{n}\left(C F_{h u, j} \times z h u_{j, 0, n}\right) \\
& +\sum_{j} \sum_{k} \sum_{n}\left(C F_{h u, j} \times\left(z h u s_{j, k, n}+z h u_{j, k, n}\right)\right)+\sum_{i}\left(C E_{c u, i} \times A c u_{i}^{\beta}\right) \\
& +\sum_{i} \sum_{j} \sum_{k}\left(C E_{i, j, k} \times A_{i, j, k}^{\beta}\right)+\sum_{j} \sum_{n}\left(C E_{h u, j} \times A h u_{j, 0, n}^{\beta}\right)+\sum_{j} \sum_{k} \sum_{n}\left(C E_{h u, j} \times\left(A h u_{j, k, n}^{\beta}+A h u s_{j, k, n}^{\beta}\right)\right) \\
& +C_{c u} \times\left(\sum_{j} q c_{j}+m_{e x t} \times \text { lheat }_{\text {condenser }}\right)+C_{f u e l}+C_{\text {tur }}+C_{\text {boil }}-C_{\text {pow }} \times w t^{\text {total }}
\end{aligned}
$$

\subsection{Model Implementation}

The formulated model is in MINLP presentation, containing a large number of continuous variables, binary variables and non-linear terms. The former kind refers to operational aspects, such as designed load, flowrate, temperature, fuel consumption, steam quantity, generated power and device size, while the later kind account for structure aspect, related to the existence of heat exchange matches and the utilization of steam. Non-isothermal mixing, heat exchange area calculation and cost calculation contribute to the non-linear terms. The model is programmed in the general modeling software GAMS and solved by the solver BARON [24], within the Windows 10 computing environment using an Intel(R) Core(TM) i7-8,700k CPU @ 3.70 GHz, 32.0 GB RAM. Here it should be noted that the global optimum cannot be always guaranteed if handling big size problems, but appropriate initial values of the variables will facilitate the search to improve the quality of solutions. 


\section{Case Study}

\subsection{Case Description}

A case is studied in this section to illustrate the proposed synthesis method. The most cost-saving network solution is expected. The case comprises four hot and four cold process streams, for which the characteristics, including heat capacity flowrates, supply temperatures and target temperatures are given in Table 1 . Supply and target temperatures of cooling water utility are $25^{\circ} \mathrm{C}$ and $35^{\circ} \mathrm{C}$. Three pressure levels of steam in low, medium and high pressure levels (LPS, MPS, HPS) are defined as $170.4{ }^{\circ} \mathrm{C}, 198.3^{\circ} \mathrm{C}$ and $263.9^{\circ} \mathrm{C}$ with the corresponding pressure, so the production and utilization of the steam should be optimized according the performance the entire system. Turbine exhaust steam condensate is $45.8^{\circ} \mathrm{C}$ [18]. Overall heat transfer coefficients are fixed at 1.0 and $0.5 \mathrm{~kW} \cdot \mathrm{m}^{-2} \cdot{ }^{\circ} \mathrm{C}^{-1}$ for steam heating and non-steam heating, respectively. The prices of boiler fuel natural gas and generated power are $0.227 \$ \cdot \mathrm{kg}^{-1}$ and $0.076 \$ \cdot \mathrm{kWh}^{-1}$ [18], respectively. Efficiencies of boiler and turbine are set to be 0.9 and 0.7 [17]. Annual operation time is $8000 \mathrm{~h} \cdot \mathrm{y}^{-1}$. Minimum heat transfer temperature difference is set to be $10^{\circ} \mathrm{C}$. Coefficients for turbine cost $a_{t u r}$ and $b_{t u r}$ are $81,594 \$ \cdot \mathrm{y}^{-1}$ and $18.52 \$ \cdot \mathrm{kWh}^{-1} \cdot \mathrm{y}^{-1}$ [18]. Coefficients for boiler cost $a_{\text {boil }}$ and $b_{\text {boil }}$ are $101,840 \$ \cdot \mathrm{y}^{-1}$ and $3.441 \$ \mathrm{~h} \cdot \mathrm{kg}^{-1} \cdot \mathrm{y}^{-1}$ [15].

Table 1. Process data of the case study.

\begin{tabular}{cccccccc}
\hline $\begin{array}{c}\text { Hot } \\
\text { Stream }\end{array}$ & $\mathbf{T}_{\text {in }}\left({ }^{\circ} \mathbf{C}\right)$ & $\mathbf{T}_{\text {out }}\left({ }^{\circ} \mathbf{C}\right)$ & $\mathbf{F C}\left(\mathbf{k W} /{ }^{\circ} \mathbf{C}\right)$ & $\begin{array}{c}\text { Cold } \\
\text { Stream }\end{array}$ & $\mathbf{T}_{\text {in }}\left({ }^{\circ} \mathbf{C}\right)$ & $\mathbf{T}_{\text {out }}\left({ }^{\circ} \mathbf{C}\right)$ & FC( $\left.\mathbf{k W} /{ }^{\circ} \mathbf{C}\right)$ \\
\hline 1 & 315 & 159 & 167 & 1 & 30 & 255 & 190 \\
2 & 238 & 195 & 220 & 2 & 49 & 219 & 100 \\
3 & 230 & 60 & 80 & 3 & 59 & 185 & 50 \\
4 & 200 & 143 & 130 & 4 & 117 & 134 & 150 \\
\hline
\end{tabular}

It is believed that the structure of HEN and the operation of utility system will impact the entire system greatly. Thus, two design schemes with two scenarios of each are investigated within the synthesis. The schemes are defined according to different condensate recovery manners. In the first scheme, condensates of exhaust steam and multi-level steam (HPS, MPS, LPS) are collected in the deaerator which works at a certain operating temperature [18], and then sent to the boiler. In the other scheme, condensates of multi-level steam are recovered without flowing through the deaerator, and exhaust steam at the turbine end is no longer needed to maintain the operating temperature of the deaerator. For each scheme, two scenarios are studied according to different HEN superstructures. In the first scenario, steam utilities are only used at stream ends. While in the second scenario, the proposed structure is adopted, as using the steam not only within inner-stage but also within inter-stage. Therefore, four situations for the whole system are studied and compared to demonstrate the method.

\subsection{Results and Discussion}

\subsubsection{Scheme 1: Deaerator is Involved in the System}

In this scheme, steam is only used at stream ends, while the deaerator is employed as cited in [18], maintaining its operating temperature at $158^{\circ} \mathrm{C}$. Figure 2 presents the structure result of Scenario 1 , which features the TAC of 3,599,059 $\$ \cdot y^{-1}$.As shown, cold process stream $\mathrm{C} 1$ is heated by hot process streams $\mathrm{H} 1, \mathrm{H} 2$ and $\mathrm{H} 3, \mathrm{C} 2$ is heated by $\mathrm{H} 2$ and $\mathrm{H} 4$, three heaters are needed at stream ends of $\mathrm{C} 2, \mathrm{C} 3$ and C4. In total, $2550 \mathrm{~kW}$ LPS, $6300 \mathrm{~kW}$ MPS and $3228 \mathrm{~kW}$ HPS are generated from utility system and sent to HEN. Besides, exhaust steam is extracted and condensed at turbine end, mixing with condensates in deaerator and maintaining its operating temperature. 


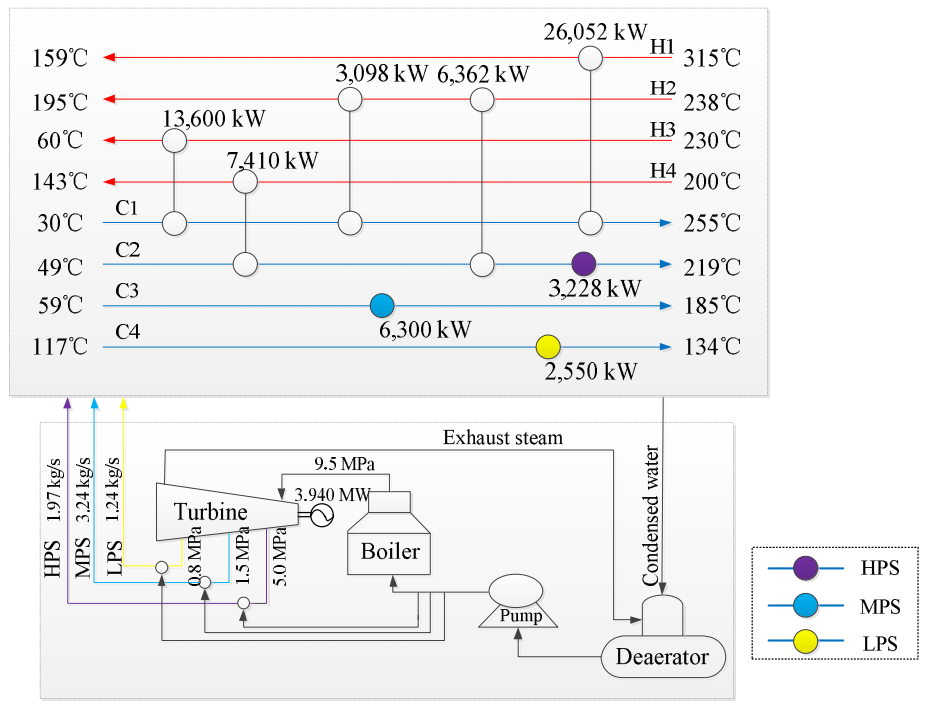

Figure 2. Structure with minimum TAC of Scenario 1.

Figure 3 shows the solution of Scenario 2, discarding the location limit on steam heaters. The TAC of the solution is $2,866,637 \$ \cdot y^{-1}$.

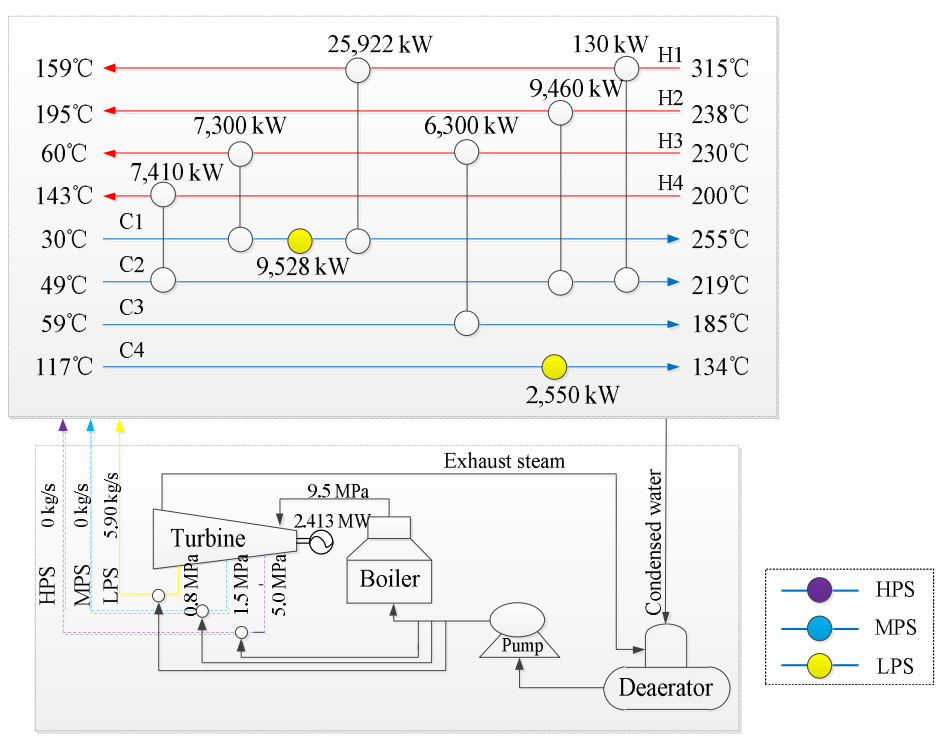

Figure 3. Structure with minimum TAC of Scenario 2.

As shown, $\mathrm{C} 1$ is heated by $\mathrm{H} 1$ and $\mathrm{H} 3, \mathrm{C} 2$ is heated by $\mathrm{H} 2$ and $\mathrm{H} 4, \mathrm{C} 3$ is heated by $\mathrm{H} 3$. It is worth noting that the originally required higher pressure steam in Figure 2 is replaced by lower pressure steam with the load of $12,078 \mathrm{~kW}$ of LPS. One heater of the two is located within the inter-stage of C1. This illustrates that the appropriate use of steam considering the inner- and inter-stage location is able to enhance the use of lower pressure steam.

The cost composition of the two scenarios is summarized in Table 2. As indicated, fuel cost of Scenario $2\left(3,240,049 \$ \cdot y^{-1}\right)$ is $32.2 \%$ lower than that of Scenario $1\left(4,782,431 \$ \cdot y^{-1}\right)$. This is because only higher pressure steam can be used at stream ends in Scenario 1 due to the temperature constraints, so the resultant high temperature condensate needs additional extracted and condensed exhaust steam to maintain the operating temperature of deaerator, leaning to the greater fuel consumption. Accordingly, the boiler cost $\left(212,203 \$ \cdot y^{-1}\right)$ and turbine cost $\left(152,718 \$ \cdot y^{-1}\right)$ of Scenario 1 are both higher than Scenario 1, while for heat exchanger investment, higher pressure steam is replaced by low pressure steam, increasing the heat transfer temperature difference and increasing heat exchanger area, 
so by adding all concerned components, equipment investment of the two scenarios make nearly no difference. In spite of the decreased power generation profit in Scenario 2, fuel costs account for most of the investment, thus finally, TAC of Scenario 2 presents a $20.4 \%$ lower than Scenario 1 . Conclusion can be made that the improved HEN superstructure provides more possibilities for the selection of multiple utilities and lower pressure steam is more economical in this system.

Table 2. Results of Scheme 1.

\begin{tabular}{|c|c|c|c|c|c|}
\hline & Scenario 1 & Scenario 2 & - & Scenario 1 & Scenario 2 \\
\hline Cost of fuel $\left(\$ \cdot y^{-1}\right)$ & $4,782,431$ & $3,240,094$ & $\begin{array}{c}\text { Heat } \\
\text { exchangers } \\
\text { investment }\left(\$ \cdot y^{-1}\right)\end{array}$ & 699,045 & 748,222 \\
\hline $\begin{array}{c}\text { Boiler } \\
\text { investment }\left(\$ \cdot y^{-1}\right)\end{array}$ & 212,203 & 176,611 & $\begin{array}{l}\text { Profit of selling } \\
\text { power }\left(\$ \cdot y^{-1}\right)\end{array}$ & $2,395,504$ & $1,467,250$ \\
\hline $\begin{array}{c}\text { Turbine } \\
\text { investment }\left(\$ \cdot y^{-1}\right)\end{array}$ & 152,718 & 125,158 & $\operatorname{TAC}\left(\$ \cdot y^{-1}\right)$ & $3,599,059$ & $2,866,637$ \\
\hline
\end{tabular}

\subsubsection{Scheme 2: Deaerator is not Involved in the System}

In Scheme 2, condensates of the steam in different levels are recovered without flowing through the deaerator. Superheated steam is desuperheated by the corresponding condensates. Two scenarios with different HEN superstructures (Scenario 3 and Scenario 4) are studied.

Figure 4 presents the obtained configuration of Scenario 3, with TAC of 2,774,184 $\$ \cdot \mathrm{y}^{-1}$. As indicated, HPS, $3228 \mathrm{~kW}$, MPS, $6300 \mathrm{~kW}$ and LPS, $2550 \mathrm{~kW}$ are used at stream ends of C2, C3 and C4 respectively. Figure 5 is the configuration solution of Scenario 4, which costs 2,670,969 \$ per year. As shown, totally $10,848 \mathrm{~kW}$ of LPS and $1230 \mathrm{~kW}$ of MPS are extracted from utility system. Besides being used within inner-stage of C1, LPS is also allocated sequentially after MPS on C2 within the inter-stage. That is to say, partial MPS is replaced by LPS in this scenario. From the resulted configuration it is implies that lower pressure steam are located within inner- and inter-stage in the improved HEN superstructure.

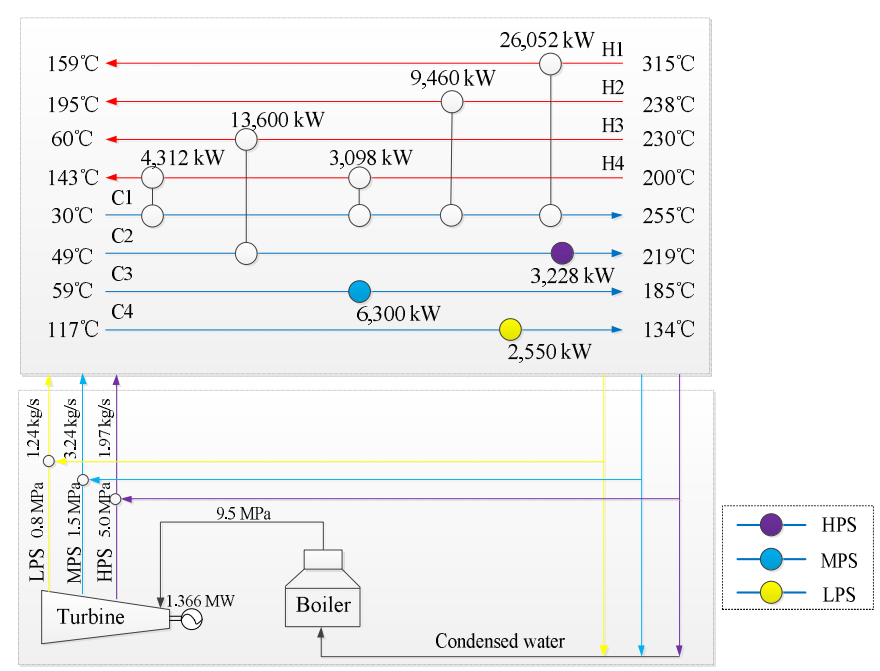

Figure 4. Structure with minimum TAC of Scenario 3.

Table 3 summarized the cost composition of Scenario 3 and 4 . Fuel cost of Scenario $4\left(2,852,680 \$ \cdot \mathrm{y}^{-1}\right)$ is increased by $5.5 \%$ compared to Scenario $3\left(2,704,636 \$ \cdot y^{-1}\right)$. As for the equipment investment, utilization of lower pressure steam in Scenario 4 results in a $10.6 \%$ higher heat exchanger cost $\left(690,124 \$ \cdot y^{-1}\right)$ than that of Scenario $3\left(624,017 \$ \cdot y^{-1}\right)$. Boiler and turbine investments of the two scenarios are nearly the same. However, more power is generated when producing lower pressure steam through the turbine in Scenario 3, due to which the profit of power generation in Scenario 
$4\left(1,156,928 \$ \cdot y^{-1}\right)$ is $39.3 \%$ higher. Combining all the above costs, the improved HEN structure gains lower TAC in total, about $3.7 \%$ decrease. It can also be concluded that lower pressure steam is more economical.

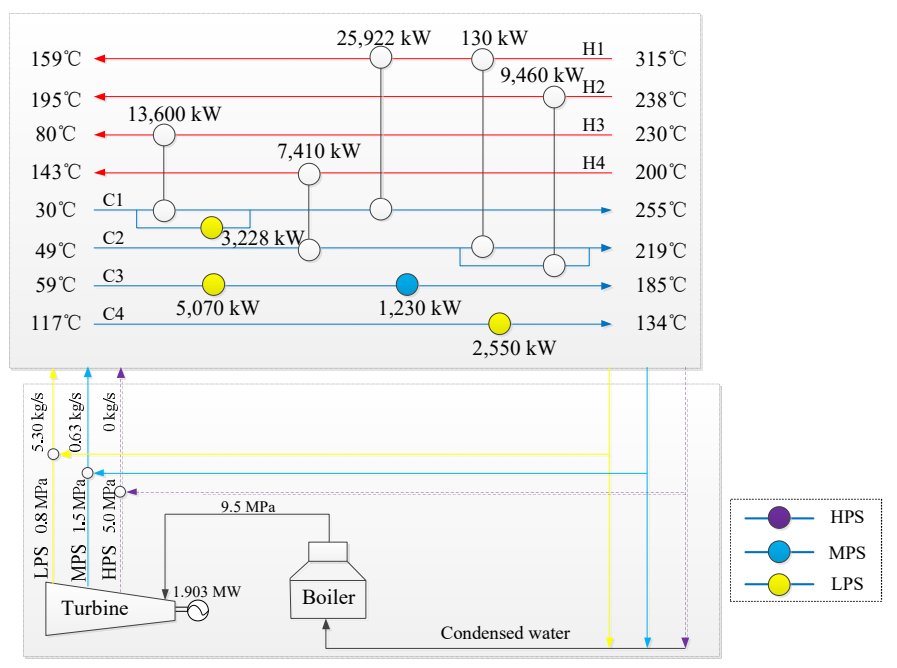

Figure 5. Structure with minimum TAC of Scenario 4.

Table 3. Results of Scheme 2.

\begin{tabular}{cccccc}
\hline & Scenario 3 & Scenario 4 & Scenario 3 & Scenario 4 \\
\hline Cost of fuel $\left(\$ \cdot \mathrm{y}^{-1}\right)$ & $2,704,636$ & $2,852,680$ & $\begin{array}{c}\text { Heat } \\
\text { exchangers } \\
\text { investment }\left(\$ \cdot \mathrm{y}^{-1}\right)\end{array}$ & 624,017 & 690,124 \\
$\begin{array}{c}\text { Boiler } \\
\text { investment }\left(\$ \cdot \mathrm{y}^{-1}\right) \\
\begin{array}{c}\text { Turbine } \\
\text { investment }\left(\$ \cdot \mathrm{y}^{-1}\right)\end{array}\end{array}$ & 169,897 & 169,149 & $\begin{array}{c}\text { powelling }\left(\$ \cdot \mathrm{y}^{-1}\right) \\
\mathrm{TAC}\left(\$ \cdot \mathrm{y}^{-1}\right)\end{array}$ & 830,622 & $1,156,928$ \\
\hline
\end{tabular}

The two schemes demonstrate that the generation and utilization of utilities have great effects on the HEN structure and equipment investment. In the design where the deaerator is employed in the utility system as cited, more exhaust steam needs to be extracted and condensed to guarantee the operating temperature by mixing with condensed water when higher pressure steam is extracted from the turbine. This will result in more fuel consumption and higher TAC because of the expensive fuel expense. Thus, using lower pressure steam is more economical. In the structure where condensed water is recovered without a deaerator, more power is generated and less heat is supplied when producing lower pressure steam with the same fuel consumption compared with higher one. It is proved that lower pressure is more economical when supplying the same amount of heat to the HEN, although with lower temperature grade. From the above analysis, it is demonstrated that, on the one hand, allowing heaters within inner- and inter-stages is able to generate a better management for utility utilization than the case of only having heaters at stream ends, because steam selections are less restricted by temperature difference constraints and more LPS can be used, which is conducive to the use of energy cascade utilization. On the other hand, a better trade-off among equipment investment, power generation and fuel consumption can be made through the optimization of the whole system with the TAC target.

\section{Conclusions}

An improved superstructure for HENs synthesis which contains the utilization of multiple utilities within inner- and inter-stages has been presented to integrate with the utility system. The coupling relationship between HENs and Rankine cycle-based utility systems is investigated and extended by 
considering various locations of steam heaters. The HEN structure has an impact on steam distribution and accordingly determines the operation of the utility system, thus in the study, the stream matches and heat transfer area of HEN, as well as the multi-level steam distribution, fuel consumption and power generation in utility system are all optimized to minimize the TAC of the whole system. Results are discussed and analyzed with case studies. The obtained economic benefits, $20.4 \%$ and $3.7 \%$ cost cuts for the cases separately, have demonstrated the method very well. It is concluded that the thermal property and quantity of steam have great effect on fuel consumption, power generation and heat transfer area, leading to an economic trade-off; relieving the location limit on steam heaters could create better solution, in terms of using more lower pressure steam not only at stream ends. Future research will be launched to develop this method to deal with the simultaneous synthesis problem of industrial park HEN and utility system with considering the selection of primary energy sources, e.g., fuel, solar, nuclear, wind, etc.

Author Contributions: Methodology, Y.S. and L.L.; validation, Y.S., L.L., Y.Z., L.Z. and J.D.; writing-original draft preparation, Y.S.; writing-review and editing, L.L., Y.Z., L.Z. and J.D.; visualization, Y.S.; supervision, L.L.; project administration, L.L.; funding acquisition, L.L. All authors have read and agree to the published version of the manuscript.

Funding: This research was funded by Natural Science Foundation of China (No.21878034 and 21776035) and the Fundamental Research Fund for Central Universities of China (DUT18LAB11).

Conflicts of Interest: The authors declare no conflict of interest.

\section{Nomenclature}

\begin{tabular}{|c|c|}
\hline \multirow{2}{*}{\multicolumn{2}{|c|}{ Indices and $\mathrm{s}$}} \\
\hline & \\
\hline$i$ & hot stream \\
\hline$j$ & cold stream \\
\hline$n$ & steam level \\
\hline$m$ & temperature location \\
\hline$k$ & stage \\
\hline$M$ & total number of temperature location \\
\hline \multicolumn{2}{|c|}{ Parameters } \\
\hline$F H_{i}$ & heat capacity flow rate of hot stream \\
\hline$F C_{j}$ & heat capacity flow rate of cold stream \\
\hline $\operatorname{thin}_{i}$ & inlet temperature of hot stream \\
\hline thout $_{i}$ & outlet temperature of hot stream \\
\hline $\operatorname{tcin}_{j}$ & inlet temperature of cold stream \\
\hline tcout $_{j}$ & outlet temperature of cold stream \\
\hline tcuin & inlet temperature of cold utility \\
\hline tcuout & outlet temperature of cold utility \\
\hline$t h u_{j, k, n}$ & temperature of hot utility $\mathrm{n}$ within inter-stage $\mathrm{k}$ \\
\hline thus $_{j, k, n}$ & temperature of hot utility $\mathrm{n}$ within inner-stage $\mathrm{k}$ \\
\hline$h 1$ & heat transfer coefficient for hot utility \\
\hline$h$ & heat transfer coefficient for process streams \\
\hline$\gamma$ & a sufficiently large constant number \\
\hline effturb & efficiencies of turbine \\
\hline effboil & efficiencies of boiler \\
\hline ahour & 8000 hours per year \\
\hline heatcap & heat content of boiler fuel \\
\hline$C_{c u}$ & cost coefficient for cold utility \\
\hline$C_{\text {pow }}$ & cost coefficient for power \\
\hline cfuel & cost coefficient for boiler fuel \\
\hline$C E, C F, \beta$ & parameters for cost of heat exchanger \\
\hline
\end{tabular}


Binary variables

$z_{i, j, k}$
$z c u_{i}$
$z h u_{j, k, n}$
$z h u s_{j, k, n}$

Continuous variables

$q_{i, j, k}$

$q c_{i}$

$q h u_{j, k, n}$

qhus $_{j, k, n}$

$q c_{\text {condenser }}$

$t i_{i, m}$

$t j_{j, m}$

$t h_{i, j, k}$

$t c_{i, j, k}$

tcsp $p_{j, k, n}$

$f h s_{i, j, k}$

$f c s_{i, j, k}$

$f \operatorname{cs} p_{j, k, n}$

$\operatorname{fcsk}_{j, k, n}$

$A_{i, j, k}$

$A c u_{i}$

$A h u_{j, k, n}$

Ahus $_{j, k, n}$

qsteam $_{n}$

msteam $_{n}$

$m_{\text {ext }}$

$w t^{\text {total }}$

$C_{\text {fuel }}$

$C_{\text {tur }}$

$C_{\text {boil }}$ the existence of matching between hot and cold process streams

the existence of matching between hot process streams and cold utility

the existence of matching between cold process streams and hot utility $n$ within inter-stage $\mathrm{k}$

the existence of matching between cold process streams and hot utility $n$ within inner-stage $\mathrm{k}$

heat load between hot and cold process streams within inner-stage $\mathrm{k}$

heat load between hot stream $i$ and cold utility

heat load between cold stream $\mathrm{j}$ and hot utility $\mathrm{n}$ within inter-stage $\mathrm{k}$

heat load between cold stream $\mathrm{j}$ and hot utility $\mathrm{n}$ within inner-stage $\mathrm{k}$

cold utility requirement for exhaust steam

temperature of hot stream

temperature of cold stream

outlet temperature of split branch of hot stream matching with cold stream $j$

outlet temperature of split branch of cold stream matching with hot stream i

outlet temperature of split branch of cold stream matching with utility $n$

heat capacity flow rate of split branch of hot stream matching with cold stream $j$

heat capacity flow rate of split branch of cold stream matching with hot stream i

heat capacity flow rate of split branch of cold stream matching with utility $n$ within

inner-stage $\mathrm{k}$

heat capacity flow rate of split branch of cold stream matching with utility $n$ within inter-stage $\mathrm{k}$

area of heat exchanger for cold and hot process streams

area of heat exchanger for hot stream i and cold utility

area of heat exchanger for cold stream $j$ and hot utility $n$ within inter-stage $k$

area of heat exchanger for cold stream $\mathrm{j}$ and hot utility $\mathrm{n}$ within inner-stage $\mathrm{k}$

total heat demand of steam $n$

total mass demand of steam $n$

mass flow rate of exhaust steam

power generation of utility system

fuel cost

turbine cost

boiler cost

\section{References}

1. Linnhoff, B.; Hindmarsh, E. The pinch design method for heat exchanger networks. Chem. Eng. Sci. 1983, 38, 745-763. [CrossRef]

2. Papoulias, S.A.; Grossmann, I.E. A structural optimization approach in process synthesis I: Utility systems. Comput. Chem. Eng. 1983, 7, 695-706. [CrossRef]

3. Yee, T.F.; Grossmann, I.E. Simultaneous optimization models for Heat Integration-II. Heat exchanger network synthesis. Comput. Chem. Eng. 1990, 14, 1165-1184. [CrossRef]

4. Costa, A.L.H.; Queiroz, E.M. An extension of the problem table algorithm for multiple utilities targeting. Energy Convers. Manag. 2009, 50, 1124-1128. [CrossRef]

5. Salama, A.I.A. Optimal assignment of multiple utilities in heat exchange networks. Appl. Therm. Eng. 2009, 29, 2633-2642. [CrossRef]

6. Shenoy, U.V.; Sinha, A.; Bondyopadhyay, S. Multiple utilities targeting for heat exchanger networks. Chem. Eng. Res. Des. 1998, 76, 259-272. [CrossRef]

7. Isafiade, A.J.; Fraser, D.M. Interval-based MINLP superstructure synthesis of heat exchange networks. Chem. Eng. Res. Des. 2008, 86, 245-257. [CrossRef]

8. Ponce-Ortega, J.M.; Serna-González, M.; Jiménez-Gutiérrez, A. Synthesis of heat exchanger networks with optimal placement of multiple utilities. Ind. Eng. Chem. Res. 2010, 49, 2849-2856. [CrossRef] 
9. Na, J.; Jung, J.; Park, C.; Han, C. Simultaneous synthesis of a heat exchanger network with multiple utilities using utility substages. Comput. Chem. Eng. 2015, 79, 70-79. [CrossRef]

10. Zhang, H.; Cui, G.; Xiao, Y.; Chen, J. A novel simultaneous optimization model with efficient stream arrangement for heat exchanger network synthesis. Appl. Therm. Eng. 2017, 110, 1659-1673. [CrossRef]

11. Pavão, L.V.; Costa, C.B.B.; Ravagnani, M.A.S.S. An enhanced stage-wise superstructure for heat exchanger networks synthesis with new options for heaters and coolers placement. Ind. Eng. Chem. Res. 2018, 57, 2560-2573. [CrossRef]

12. Ma, J.; Chang, C.L.; Wang, Y.F.; Feng, X. Multi-objective optimization of multi-period interplant Heat Integration using steam system. Energy 2018, 159, 950-960. [CrossRef]

13. Klemeš, J.J.; Dhole, V.R.; Raissi, K.; Perry, S.J.; Puigjaner, L. Targeting and design methodology for reduction of fuel, power and $\mathrm{CO}_{2}$ on total sites. Appl. Therm. Eng. 1997, 17, 993-1003. [CrossRef]

14. Liew, P.Y.; Alwi, S.R.W.; Varbanov, P.S.; Manan, Z.A.; Klemeš, J.J. Centralised utility system planning for a total site heat integration network. Comput. Chem. Eng. 2013, 57, 104-111. [CrossRef]

15. Chen, C.L.; Lin, C.Y. Design of entire energy system for chemical plants. Ind. Eng. Chem. Res. 2012, 51, 9980-9996. [CrossRef]

16. Hipólito-Valencia, B.J.; Rubio-Castro, E.; Ponce-Ortega, J.M.; Serna-González, M. Optimal integration of organic rankine cycles with industrial processes. Energy Convers. Manag. 2013, 73, 285-302. [CrossRef]

17. Goh, W.S.; Wan, Y.K.; Tay, C.K.; Ng, R.T.L. Automated targeting model for synthesis of heat exchanger network with utility systems. Appl. Energy 2016, 162, 1272-1281. [CrossRef]

18. Luo, X.; Huang, X.; El-Halwagi, M.M.; Ponce-Ortega, J.M. Simultaneous synthesis of utility system and heat exchanger network incorporating steam condensate and boiler feedwater. Energy 2016, 113, 875-893. [CrossRef]

19. Martelli, E.; Elsido, C.; Mian, A.; Marechal, F. Minlp model and two-stage algorithm for the simultaneous synthesis of heat exchanger networks, utility systems and heat recovery cycles. Comput. Chem. Eng. 2017, 106, 663-689. [CrossRef]

20. Elsido, C.; Martelli, E.; Grossmann, I.E. A Bilevel Decomposition Method for the Simultaneous Synthesis of Utility Systems, Rankine Cycles and Heat Exchanger Networks, Proceedings of the 28th European Symposium on Computer-Aided Process Engineering (ESCAPE28), Graz, Australia, 10-13 June 2018; Friedl, A., Klemeš, J.J., Radl, S., Varbanov, P.S., Wallek, T., Eds.; Elsevier: Kidlington, UK, 2018; Volume 43, pp. 373-378.

21. Chang, C.; Chen, X.; Wang, Y.; Feng, X. Simultaneous optimization of multi-plant Heat Integration using intermediate fluid circles. Energy 2017, 121, 306-317. [CrossRef]

22. Huang, X.; Lu, P.; Luo, X.; Chen, J.; Yang, Z.; Liang, Y.; Wang, C.; Chen, Y. Synthesis and simultaneous MINLP optimization of heat exchanger network, steam Rankine Cycle, and organic Rankine Cycle. Energy 2020, 195, 116922. [CrossRef]

23. Chen, J. Comments on the improvements on a replacement for the logarithmic mean. Chem. Eng. Sci. 1987, 42, 2488-2489. [CrossRef]

24. Rosenthal, R.E. GAMS-A user's guide. GAMS Dev. Corp. 2010, 49, 397-400.

(C) 2020 by the authors. Licensee MDPI, Basel, Switzerland. This article is an open access article distributed under the terms and conditions of the Creative Commons Attribution (CC BY) license (http://creativecommons.org/licenses/by/4.0/). 